\title{
A Capital Federal de Artur Azevedo: questões de análise dramatúrgica
}

\author{
Alberto Tibaji (Alberto Ferreira da Rocha Junior) \\ Universidade Federal de São João del Rey
}

\section{Introdução}

Este artigo é resultado das reflexões relativas à pesquisa que atualmente desenvolvemos intitulada Concepções de cultura na obra de Artur Azevedo. Para o desenvolvimento da mesma, contamos com o auxílio de um bolsista $\mathrm{PIBIC/FAPEMIG} \mathrm{e} \mathrm{de} \mathrm{dois} \mathrm{bolsistas} \mathrm{PIBIC} / \mathrm{CNPq}^{2}$.

O objetivo geral da pesquisa é analisar peças do comediógrafo maranhense e observar concepções de cultura presentes tanto nos textos quanto em algumas encenações dos mesmos. Foram escolhidas as peças: A capital federal, O mambembe e A filha de Maria Angu ${ }^{3}$.

Nosso estudo insere-se na vertente atual de estudos teatrais que enfatizam as relações entre texto e cena. Como disse Fischer-Lichte, no século XIX, o teatro era predominantemente definido por sua capacidade de transmitir ou mediar obras literárias (1999: 169) ${ }^{4}$. É a partir do surgimento do diretor teatral e do encenador ${ }^{5}$ que há uma grande valorização do que hoje em dia costumamos chamar de performance e que no início do século XX foi chamado de "teatralidade" 6 .

Inserem-se dentro dessa tendência algumas obras já clássicas: Drama in performance de Raymond Williams, cujo título já deixa evidente sua preocupação com a história do espetáculo teatral. Nessa obra, cuja primeira publicação data de $1954^{7}$, Williams analisa desde Antígona de Sófocles até Esperando Godot de Samuel Beckett, levando-se em consideração texto, cena e condições de representação (conditions of performance).

No trabalho de análise teatral desenvolvido por Anne Ubersfeld em seu Lire le théâtre ${ }^{8}$, publicado pela primeira vez em 1977, fica explícito que a análise pode ser feita tanto a partir do texto como a partir do espetáculo e que elas não são necessariamente coincidentes ${ }^{9}$. Em âmbito brasileiro, citamos, a título de exemplo, as discussões realizadas dentro dos Grupos de Trabalho História das artes do espetáculo e Dramaturgia - tradição e contemporaneidade da Associação Brasileira de Pesquisa e Pós-graduação em Artes Cênicas ${ }^{10}$. 
Dentro dessa perspectiva, pretendemos colaborar para as discussões em curso sobretudo a partir de dois objetivos:

1. Repensar os modelos de análise dramatúrgica, abandonando a idéia de que é necessário um modelo estático e aproximarmo-nos da idéia de investigação antropológica e etnológica. Para compreender a peça teatral é necessário freqüentá-la, conviver e observar suas especificidades, o que requer uma abordagem culturalista. Esse convívio inclui o acesso aos documentos relacionados às representações dos textos. Escolhemos o universo do teatro cômico e musicado de Artur Azevedo para a investigação dessas especificidades.

2. Contribuir para a discussão em torno de leituras dos "clássicos" do teatro cômico brasileiro ${ }^{11}$. Sua valorização pela crítica especializada e pelos historiadores do teatro com freqüência passa por uma concepção de cultura que associa esse teatro à idéia do nacional-popular, sendo que a representação do texto busca freqüentemente preservar o passado. Assim, a cena assume contornos museológicos, no sentido de restauração do passado hic et nunc ${ }^{12}$.

\section{Pressupostos da análise dramatúrgica}

As análises de textos da dramaturgia cômica brasileira utilizam categorias que freqüentemente partem de dois pressupostos básicos:

1. Compreender científica e objetivamente um texto teatral é buscar um modelo geral aplicável a qualquer texto teatral;

2. Compreender científica e objetivamente um texto teatral é ater-se à sua materialidade, a suas características imanentes ou empíricas.

A objeção que fazemos ao primeiro pressuposto é que, se por um lado obtemos padrões estáveis para a compreensão de um texto que nos permitem compará-lo a outros textos, por outro, o modelo utilizado para analisar a peça esbate as peculiaridades do objeto, sendo que, às vezes, essas peculiaridades são o traço fundamental da peça. Alguns exemplos aqui já podem elucidar o que queremos dizer. Quando nos debruçamos sobre um drama de Ibsen ou de Tchekov, o personagem pede que a análise se dedique aos meandros de sua psicologia. Entretanto, ainda que utilizemos a noção de personagem, se nos debruçarmos sobre uma comédia de Martins Pena, o personagem pede que a análise se dedique a quê? Noutras palavras, para analisar um personagem dos dramas de Ibsen e Tchekov devo partir do pressuposto que esse personagem 
é redondo/esférico - para utilizar a já antiga denominação criada por Forster (1970) - enquanto para analisar um personagem de comédias de Martins Pena devo partir do pressuposto que esse personagem é plano. Da mesma forma, se vou analisar o conflito gerador da ação dramática devo levar em consideração que o conflito a ser desenvolvido por personagens redondos não pode ser analisado como um conflito a ser desenvolvido por personagens planos. Temos aí, portanto, uma dificuldade que é: uma única categoria varia de acordo com o objeto a ser analisado. Além disso, o hábito de analisar textos teatrais utilizando categorias como: personagem, enredo, tema, conflito, ação dramática etc. fez com que durante longo tempo características determinadas e determinantes de certos textos passassem despercebidas. O exemplo que nos parece mais contundente é o da ausência freqüente dos procedimentos de fabricação de comicidade como parâmetro de análise de peças de teatro cômico. É com os "mapas empíricos" para análise de textos de Ariano Suassuna, elaborados dentro do Projeto Integrado de Pesquisa Um estudo sobre o cômico: o teatro popular no Brasil entre ritos e festas, que esse item passa a ser considerado dentro do tópico diálogos ${ }^{13}$.

É justamente dentro do âmbito do referido Projeto Integrado que começam a ser inseridas categorias de abordagem que fogem àquelas tradicionalmente utilizadas e que citamos acima: o item Fontes utilizado nas análises de Inês Moreira (2000) e o item Movência utilizado na análise de Filomena Chiaradia (1997). Portanto, apesar de utilizar vários tópicos consagrados, o mapa proposto no artigo de Moreira e a análise efetuada na dissertação de Mestrado de Chiaradia já apontam para a valorização de especificidades de textos teatrais ${ }^{14}$.

A objeção que fazemos ao segundo pressuposto implica em questões de fundo teórico e também metodológico. A ênfase no caráter empírico ou imanente da análise está fundada na crença de que é possível obtermos uma posição neutra que garanta a objetividade do nosso conhecimento, noutras palavras, que nos garanta sua cientificidade ${ }^{15}$. Na verdade, há aí uma valorização da materialidade da peça, como se ela fosse feita apenas pelas palavras impressas na página ou pela concretude cênica. O sentido de uma peça - e é para investigá-lo que a analisamos - se constrói temporalmente, ou seja, historicamente, trazendo elementos do passado, do presente e do futuro. Comumente a análise de um espetáculo parece esgotar-se na mera descrição física de sua materialidade, numa espécie de registro em palavras da variedade de elementos cênicos utilizados durante o espetáculo: som, cenário, gesto, maquiagem, 
figurino, iluminação, diálogos etc. ${ }^{16}$.

O fundamento teórico de nossa pesquisa encontra-se sobretudo em Verdade e Método do filósofo alemão Hans-Georg Gadamer (1900-2002). Em sua reflexão sobre a "experiência da arte", Gadamer (1976) elabora o conceito de mediação total. Em termos sucintos, trata-se de reconhecer na "representação" o modo de ser da própria obra de arte (p. 42) ${ }^{17}$. Em termos teatrais: a execução de um drama também não pode ser separada do próprio drama como alguma coisa que não pertenceria ao seu ser essencial (p. 42) 18. É por isso que Gadamer vai falar da não-diferenciação entre a obra e sua mediação: a pretensão à exatidão de toda representação simplesmente confirma que a não-distinção entre a mediação da obra e a própria obra constitui a verdadeira experiência da obra (p. 46-7) ${ }^{19}$. Com isso Gadamer afirma uma identidade da obra perpassada constitutivamente pela idéia de temporalidade. Noutras palavras: é sempre a mesma peça, sendo sempre outra. Nas palavras de Gadamer, a obra de arte é o ente que só é na medida em que está sempre tornando-se outro (p. 50) ${ }^{20}$.

Interessam-nos aqui ainda mais dois aspectos fundamentais de sua reflexão. O primeiro é o caráter ocasional de toda obra, levando o filósofo a colocar em pé de igualdade as obras supostamente atemporais e aquelas consideradas datadas. Há, então, uma mudança no estatuto de obras como o retrato, a poesia dedicatória, a alusão cômica, a parábase da comédia grega, a caricatura etc. (cf. p. 72-89). A ocasionalidade da obra está intrinsecamente ligada a uma continuidade de sentido que liga a obra de arte ao mundo da existência (p. 61) ${ }^{21}$.

A segunda conseqüência é a valorização do que atualmente chamamos de recepção da obra e que Gadamer explicita, quando discorre sobre a posição limite da literatura (p. 89-94) 22 .

A experiência da identidade entre obra e mediação (a mediação total) é levada ao extremo quando se passa para o domínio da literatura. Nesse caso, apenas quando há um leitor lendo a obra é que a obra é. Como diz Gadamer, o conceito de literatura não existe inteiramente sem referência àquele que recebe a obra (p. 91) ${ }^{23}$.

A partir disso o que se percebe é a importância da historicidade para a compreensão de peças teatrais na medida em que seu sentido se perfaz nas variadas leituras realizadas pelo autor, pelo público e pelos artistas em geral. Em relação ao aporte cultural, trata-se sobretudo de vencer valores inerentes a algumas análises dramatúrgicas já consagradas e buscar a especificidade de 
gêneros e de modos de produção artísticos.

\section{A ação dramática em $A$ capital federal}

Compreendemos ação dramática aqui como resultado de um conflito: ação que não é estática, ao contrário: é dinâmica. Enfim, a ação dramática, o movimento interior, o devir, constituem a própria essência de uma peça de teatro e são conseqüência do conflito (Pallottini, 1988: 41).

A partir da leitura de textos da história do teatro brasileiro, pode-se resumir a ação dramática de $A$ capital federal assim: um casal de roceiros de S. João do Sabará chega ao Rio de Janeiro em busca do noivo de sua filha que prometera casamento, mas desaparecera. Junto com o casal vêm a filha, um filho e uma espécie de mucama, a mulata Benvinda. Aos poucos, cada um dos membros da família é "contaminado" pelo "micróbio da pândega": a mulata é seduzida por uma espécie de cafetão, o menino passa a participar de corridas de bicicletas e de apostas e o pai envolve-se com uma cocote. Ao final, depois de se desiludirem com a capital federal, voltam todos para a fazenda, inclusive o noivo da filha.

Vejamos o que aconteceria se utilizássemos os procedimentos de análise de João das Neves (1987) ${ }^{24}$ :

1) A família mineira, que acabara de chegar de viagem, é recebida pelo gerente do Grande Hotel da Capital Federal como novos hóspedes, coincidentemente lá hospeda-se Gouveia. Figueiredo encanta-se com Benvinda.

2) Numa imobiliária, Quinota lê a carta que Benvinda recebera de Figueiredo enquanto esperam Eusébio conseguir uma indicação de alguma casa para alugarem, pois, para Eusébio a hospedagem no hotel era muito dispendiosa.

3) No largo do Carioca, Benvinda encontra-se e foge com Figueiredo, conforme este lhe propusera na carta. No mesmo local, Gouveia, assediado por Lola, consegue livrar-se dela, porém tem o azar de encontrar-se pela primeira vez com Eusébio, Fortunata, Quinota e Juquinha. Juntos vão para o hotel e Gouveia tenta justificar seu sumiço.

4) Lola e Gouveia encontram-se casualmente na rua e saem juntos, sendo vistos por Eusébio, Fortunata e Quinota; esta, chorosa, é consolada pelo pai. 
Gouveia revela à Lola que deve casar-se com Quinota. Lola põe-se a lamentar, mas ao saber que ele está falido, desprezao sarcasticamente e não mais o quer.

6) Eusébio decide encontrar Lola e dizer-lhe que se afaste de Gouveia. Esta, que já não tinha mais interesse nesse relacionamento, finge consentir para, em contrapartida, seduzir o fazendeiro, que se entrega aos seus encantos e passa a viver desvairadamente junto à cocote.

7) No baile à fantasia na casa de Lola, Benvinda e Eusébio inesperadamente reconhecem-se espantados.

8) Lola e Lourenço, que já tramavam contra Eusébio, conseguem subtrair ardilmente dois contos de réis do fazendeiro. Duquinha, um jovem apaixonado, visita Lola que não hesita em explorá-lo também.

9) No Belódromo Nacional, Eusébio ganha grande quantia de dinheiro apostando, e descobre, por fim, que apostara em Juquinha. Benvinda rompe com Figueiredo.

10) Lola conta às amigas que Eusébio flagrara Duquinha e ela se beijando na sala, e por isso a abandonara, e ainda diz que Lourenço havia furtado todas suas jóias e dinheiro que guardava no cofre, deixando-lhe uma carta. Mas Lourenço não consegue fugir é é pego na rua.

11) Gouveia e Eusébio encontram-se na rua e arrependidos voltam para junto de Quinota e Fortunata. Benvinda também retorna arrependida.

12) Enfim todos são perdoados e decidem não mais permanecer na capital e voltar para a fazenda em Minas. (Monteiro, 2003: 2-3).

Nesse caso não teríamos mais do que um relato das ações superficiais dos personagens. João das Neves propõe que cada um desses segmentos seja novamente dividido em momentos. O exemplo mais expressivo da pouca utilidade de tal método para alguns tipos de peças é a análise que o autor empreende de Vestido de noiva de Nelson Rodrigues. A necessidade de relatar cronologicamente os fatos deixa de lado a mais importante característica do referido texto: o jogo com os planos da realidade, alucinação e memória.

Outra possibilidade seria pensar na ação dramática a partir das observações de Pallottini (1988). Agora é fundamental observar o conflito gerador 
da mesma: uma família busca o noivo da filha e este consegue sempre escapar. A peça termina com o fim do conflito quando Gouveia decide casar-se com a moça e ir morar em São João do Sabará ${ }^{25}$.

Se utilizarmos a grade proposta por Ubersfeld a partir da metodologia da análise do discurso, dificilmente sairíamos dessa descrição. Teríamos como sujeito da ação dramática a família de São João do Sabará que busca "resgatar" Gouveia. Como oponentes (opposants) teríamos dois personagens urbanos (Lola e Figueiredo) e características da cidade (o jogo, a prostituição etc.). É interessante notar que, a partir do momento em que a família enquanto grupo é considerada sujeito da ação, torna-se difícil perceber qual seria o adjuvante (adjuvant) da mesma. Ao nosso ver, são justamente aqueles que exercem inicialmente a função de oponentes que se deslocam, a partir de determinado momento, e passam a exercer a função de adjuvantes.

Um dos problemas que se apresenta para todos esses tipos de análise é uma característica do teatro cômico: a grande quantidade de cenas episódicas. Freqüentemente, em peças cômicas, as cenas isoladas ganham tanto destaque quanto a ação dramática. Podemos afirmar que os obstáculos que se impõem à família do Sr. Eusébio tomam tal proporção que chegam a superar o conflito anteriormente chamado de principal. Por exemplo: a família só aparece na cena nove do primeiro quadro e fica apenas mais uma cena no palco. $\mathrm{O}$ segundo quadro gira em torno da dificuldade de encontrar lugar para morar no Rio de Janeiro e pouco aborda a busca do noivo fugitivo. O sexto, sétimo e oitavo quadros se passam na casa de Lola e mostram as artimanhas que a cocote utiliza para manter o fazendeiro sob seu poder. O nono quadro é uma corrida de bicicletas e o décimo quadro gira novamente em torno da cocote. Enfim, a sensação que se tem é de que a peça é constituída em grande parte pelos obstáculos/problemas da cidade. Talvez o melhor exemplo da estrutura da peça seja justamente o ato II. Eusébio chega na casa de Lola com o intuito de convencê-la a largar Gouveia, o noivo de sua filha, mas é seduzido pela espanhola, deixando de lado seu objetivo principal. É como se essa situação fosse metonimicamente a situação da peça como um todo: a família chega na cidade com um determinado objetivo, mas dele vai se desviando, com exceção de Fortunata e Quinota. Ao contrário do que seria de se esperar da ação dramática, a peça não é constituída pelo esforço do protagonista em vencer os obstáculos, mas por todos os desvios que afastam o protagonista de seu objetivo maior. Com isso, o que o dramaturgo obtém é uma ênfase nas cenas episódicas, favorecendo um certo tipo de comicidade. 
Essa característica pode ser identificada no depoimento de André Paes Leme, diretor do espetáculo de 1997 no Centro Cultural Banco do Brasil (Rio de Janeiro):

[A capital federal] não é uma peça psicológica ou fechadinha numa personagem ou duas, num conflito especifico. Esse conflito explode para vários outros pequenos conflitos e situações secundárias. Se você retira essas situações secundárias, a peça passa a ter uma única função, que seria contar aquele episódio. Então, é fundamental, para conseguir essa visão do todo, que você mantenha esses conflitos secundários. Não só manter como valorizá-los de uma forma bem clara, bem nítida (Paes Leme, 2004: 18).

\section{A Capital Federal: do palco à página}

A partir da leitura dos jornais das épocas escolhidas ${ }^{26}$, pode-se perceber que os principais atores da peça, aqueles que merecem mais destaque da crítica ou dos anúncios, são aqueles que fazem Eusébio e Lola. Artur Azevedo (1897) já nos dá uma pista no seu rodapé de $A$ notícia, quando diz que uma simples comédia saía do gênero dos espetáculos atuais [daquela época] do Recreio Dramático. Ele fez o texto para a empresa Fernandes, Pinto \& Companhia, a pedido do ator Brandão, que interpretou Eusébio e criou personagens destinados a determinados atores como o de Lola para a atriz espanhola Pepa Ruiz (Azevedo, 1897). Tudo isso combina com o fato de Eusébio e Lola serem os personagens que aparecem mais vezes em $A$ capital federal: em 25 cenas e em 23 cenas respectivamente, num total de 68 cenas ${ }^{27}$.

A importância de Eusébio e Lola é reiterada pelos atores e atrizes que interpretaram os papéis. Em 1897, como já dissemos, esses dois personagens foram desempenhados por Brandão e Pepa Ruiz. Em relação ao primeiro, sua alcunha já é o bastante para termos uma idéia da fama do ator: Brandão, o popularíssimo. O sucesso de público que o ator obtinha é sublinhado por uma crítica que comenta a volta de Brandão em 1915 a uma de suas melhores criações: a reprise tinha ainda outra grande atração. Lá estava a defendê-la, com toda a sua veia cômica, Brandão, o popularíssimo, o velho Brandão, o ator de revista e burleta que, entre nós não tem substituto: lá estava Brandão na sua grande criação - Sô Eusébio. (Gazeta Teatral. No S. Pedro "A capital federal”. In: Gazeta de Notícias, 18 de abril de 1915, p. 7). Quanto à Pepa: [Pepa Ruiz] que viria ao Brasil em temporadas de circunstância, para afinal 
tornar-se verdadeiro ídolo de platéias entusiasmadas que lhe exigiram a presença definitiva (Ruiz, 1988: 30). ${ }^{28}$

Para reafirmar nossa hipótese poderíamos utilizar um trecho da entrevista concedida pelo diretor André Paes Leme que, ao comentar a distribuição dos personagens para sua montagem em 1997, disse o seguinte: o elenco também foi todo selecionado para o espetáculo. Eram alguns amigos anteriores. Alguns já tradicionalmente com um potencial vocal. E os dois atores protagonistas... É... Não, protagonistas não... A Lola e o ... (2004: 9). Há no depoimento de Paes Leme duas pistas interessantes. Em primeiro lugar o fato de o diretor carioca chamar Lola e Eusébio de protagonistas e depois se corrigir, já que na maioria das vezes a ação dramática da peça é pensada a partir da família de roceiros. Em segundo lugar, André não fala de personagens protagonistas, que é a expressão comum no jargão teatral. Ele faz uma pequena confusão e diz "atores protagonistas", o que reitera nossa idéia da centralidade desses dois personagens em $A$ capital federal, já que eles são sempre distribuídos para os intérpretes mais famosos da companhia.

Considerando-se essas observações, podemos propor que, ao invés de utilizarmos a categoria "ação dramática" para compreendermos essa "comédiaopereta de costumes brasileiros", podemos pensar a estrutura da peça a partir desses dois personagens, que, se não são ambos os mais importantes para a anedota da peça, são aqueles que possibilitam a exibição dos melhores desempenhos atoriais. A estrutura da peça pode ser imaginada como o caminho para o encontro de duas linhas diferentes, sendo que cada uma refere-se ao desempenho de um ator/personagem. O clímax de $A$ capital federal não está relacionado ao momento crucial do conflito propulsor da ação dramática, mas é o momento em que os dois intérpretes/personagens mais importantes se encontram pela primeira vez na peça. O cruzamento dessas duas linhas se dá na cena 3 , quadro 6 , ato II, portanto no meio do segundo ato da peça ${ }^{29}$. É a cena em que Lola seduz o fazendeiro. A importância dessa cena é reiterada por algumas referências explícitas à mesma em críticas jornalísticas:

depois de uma cena extraordinária, magistralmente escrita e otimamente representada, Lola e Eusébio ficam sendo amantes (CAPITAL federal, Gazeta da tarde, 10/02/1897, p. 2. Grifos do autor.);

a cena da sedução do roceiro foi com muito brilho representada (A CAPITAL federal, O país, 11/02/1897, p.2);

Era a festa de Irene Esquirós, e essa inteligente artista cantora, 
foi a "Lola", uma das melhores que o Rio tem aplaudido. Irene sustenta com a capacidade artística que toda gente lhe reconhece, a linha do papel. "Sô Ozébio" foi o nosso Leonardo e isto basta para que se saiba o que valeu a cena capital do $2^{\circ}$ ato. (TEATRO S. José, A imprensa, 10/07/1909, p.4).

\section{Da ação à fábula}

Em relação à categoria ação dramática, pudemos observar que ela não é muito fértil para a análise da peça. No caso, o contato com as fontes primárias - críticas e anúncios publicados em jornais cariocas - abriu-nos a possibilidade de pensar a estrutura básica do texto a partir do desempenho dos atores e não a partir das ações superficiais da anedota.

A bem da verdade, durante a pesquisa, não utilizamos nem mesmo a categoria ação dramática para análise da peça e sim a de fábula. Referimo-nos aqui ao conceito de fábula de Brecht.

Destacar a fábula não é, para Brecht, descobrir uma história universalmente decifrável e inserida no texto sob sua forma definitiva. "Procurando a fábula" o leitor e o encenador expõem seu próprio ponto de vista sobre a realidade que desejam representar: "A fábula não é simplesmente constituída por uma história extraída da vida em comum dos homens, tal como poderia ter-se desenrolado na realidade; ela é feita de processos dispostos de maneira a expressarem a concepção que o fabulador tem da sociedade" (Brecht apud Pavis, 1999: 159)

No que diz respeito à fábula de $A$ capital federal seria mais interessante, ao invés de pensar num conflito entre personagens, pensar em conflito de valores culturais, como a cidade e o campo ou entre o nacional e o estrangeiro. O autor, Artur Azevedo, ao invés de construir sua peça a partir de um conflito central sustentado por personagens, a ser solucionado no final, constrói uma cena de embate cultural. Se, por um lado, no fim da peça, seu conflito superficial está solucionado - Gouveia volta com a família para Sabará -, por outro, o conflito entre os valores urbanos e os rurais não é solucionado.

Nesse caso a cena de $A$ capital federal poderia ser pensada como o espaço de lutas de valores: o gerente do Grande Hotel defende seu espaço refinado, comparável ao da cultura francesa, mas só recebe visitantes incompatíveis com seu luxo: um jogador "compulsivo", um "lançador de mulatas", uma cocote 
e uma família de roceiros. Já aqui aparece também uma contraposição entre o nacional e o estrangeiro, já que temos um hotel que para ser bom precisa ser comparável aos melhores de Paris, mas os hóspedes são brasileiros. Temos o Figueiredo que gosta das mulatas e temos o Gouveia e o Eusébio que se deixam seduzir pelos encantos da espanhola Lola. Benvinda, que se veste de francesa, mas não deixa de ser mulata, ou Eusébio que se veste janotamente, mas não deixa de ser roceiro. Benvinda se veste de Aída, Eusébio de Princês ${ }^{30}$ (quadro sete). Finalmente, o quinteto de Figueiredo com as cocotes européias, que pode ser considerado um verdadeiro duelo de raças.

Lola: Pele cândida e rosada,

Cetinosa e delicada

Sempre teve algum valor!

Figueiredo: Que tolice!

Todas: Sim, senhor!

Lola: A cor branca, pelo menos,

Era a cor da loura Vênus,

Deusa esplêndida do amor.

Figueiredo: Quem lhe disse?

Todas: Sim, senhor!

Figueiredo: Se eu da Mitologia

Fosse o reformador,

Vênus transformaria

Numa mulata!

Todas: Horror!... (Azevedo, 1987: 403).

\section{Conclusão}

As pesquisas acadêmicas na área de Teatro, em nível de Mestrado e de Doutorado, vêm incorporando objetos outrora desprezados: gêneros populares, como o melodrama, o teatro musicado, o teatro comercial, o circo-teatro, o teatro de rua, companhias teatrais, atrizes do teatro ligeiro, o teatro fora do eixo Rio de Janeiro-São Paulo etc. Uma breve reflexão sobre esses novos objetos foi feita por Mencarelli (2002). Essa mudança muito deve às contribuições dos Estudos Históricos e dos Estudos Culturais. O que se percebe, portanto, é que se revirou a lata de lixo da história do teatro brasileiro e que está sendo escrita uma história nova de nosso teatro.

Entretanto, se já houve uma transformação na escolha dos objetos, falta 
ainda uma transformação no modo de abordá-los. A tendência da antropologia teatral de Eugenio Barba - de buscar o universal a partir das diferenças culturais - vem enfraquecendo justamente uma das mais importantes características da investigação antropológica atual: a necessidade de pensar o objeto de pesquisa em sua alteridade própria. Esse impasse metodológico começou a ser apontado no campo da antropologia por Franz Boas (1858-1942). Ao discutir as teorias evolucionistas vigentes no pensamento etnológico do século XIX, Boas valorizou a especificidade das culturas estudadas. Ao invés de enquadrar os grupos sociais estudados numa escala universal da evolução das sociedades humanas, Boas lutou pelo estudo dos grupos sociais a partir de seus próprios valores e de suas particularidades. No lugar do comparativismo cultural que tinha como finalidade elaborar regras culturais universais, Boas propõe uma antropologia historicizada, que estuda os processos de desenvolvimento cultural de sociedades específicas.

O que há, então, é uma inequívoca valorização das diferenças culturais. Se essa valorização já vem ocorrendo na escolha dos objetos possíveis de investigação no campo do teatro, parece que ainda temos um longo caminho a percorrer no que diz respeito aos instrumentos utilizados para a compreensão da alteridade do objeto. Se estudamos o teatro feito pelos operários na região do ABC em São Paulo, na década de 70, ou o teatro cômico ligeiro do início do século XX, ou ainda o espaço do circo-teatro, é preciso criar abordagens que permitam compreender esses objetos.

Há aqui um problema epistemológico que precisa ser enfrentado: o objeto só pode ser conhecido na medida em que temos instrumentos adequados para conhecê-lo, mas só podemos saber se os instrumentos são adequados na medida em que já conhecemos o objeto. Ora, se nós já conhecemos o objeto não precisamos dos instrumentos e se ainda não conhecemos o objeto ficamos impossibilitados de descobrir os instrumentos apropriados para conhecê-lo.

No caso dos textos teatrais optamos pelo seguinte procedimento: trabalhar o texto em seu processo de circulação, incluindo aí suas representações e trabalhar a partir de categorias já existentes, utilizando-as não como normas a serem encontradas, mas como referências já existentes a serem testadas e a partir daí buscar as especificidades da peça.

Finalmente, é importante ressaltar que a necessidade de se utilizar parâmetros não consagrados para analisar textos considerados de vanguarda já está consolidada. No entanto, quando lidamos com textos considerados comédias de costumes, ainda há muitos horizontes a serem descortinados. 


\section{Referências}

AZEVEDO, Artur. O theatro. A noticia, Rio de Janeiro, 05 fev. 1897, p. 2. O teatro de Artur Azevedo. Rio de Janeiro: INACEN, 1983-1995, 7v. A capital federal. In: $O$ teatro de Artur Azevedo. Rio de Janeiro: INACEN, 1987, t. IV, p. 313-418.

BALL, David. Para frente e para trás. Um guia para leitura de peças teatrais. São Paulo: Perspectiva, 1999.

BORGES, Luiz Eduardo Ramos. O cômico em França Júnior: uma análise a partir do modelo bergsoniano. São Paulo, 1991. Dissertação (Mestrado em Artes) ECA/USP.

CHARTIER, Roger. Do palco à página. Publicar teatro e ler romances na época moderna - séculos XVI-XVIII. Rio de Janeiro: Casa da Palavra, 2002. CHIARADIA, Maria Filomena Vilela. A companhia de revistas e burletas do Teatro São José: a menina-dos-olhos de Paschoal Segreto. Rio de Janeiro, 1997. Dissertação (Mestrado em Teatro) UNI-RIO.

CONGRESSO Brasileiro da Associação Brasileira de Pesquisa e Pós-graduação em Artes Cênicas. (2: 2001: Salvador). Como pesquisamos? Os Grupos de Trabalho da ABRACE. Salvador: ABRACE, 2001. Memória Abrace, 3.

CONGRESSO Brasileiro da Associação Brasileira de Pesquisa e Pós-graduação em Artes Cênicas. (2: 2001: Salvador). Anais. Salvador: ABRACE, 2002. Memória Abrace, 5. $2 \mathrm{v}$.

ECO, Umberto. Interpretação e superinterpretação. São Paulo: Martins Fontes, 1997.

FISCHER-LICHTE, Erika. From text to performance: the rise of Theatre Studies as an academic discipline in Germany. In: Theatre Research International, vol. 24, n. 2, p. 168-178. 1999.

FORSTER, E. M. Aspects of the novel. Harmondsworth: Penguin Books, 1970. GADAMER, Hans Georg. Vérité et méthode. Les grandes lignes d'une herméneutique philosophique. Paris: Seuil, 1976.

JAUSS, Hans Robert. A estética da recepção: colocações gerais. In: JAUSS, H. R. et al. A literatura e o leitor. Textos de estética da recepção. Rio de Janeiro: Paz e Terra, 1979.

KOZWAN, Tadeusz. Le Tartuffe de Molière dans une mise-en-acène de Roger Planchon. In: JACQUOT, Jean (org.). Les voies de la création théâtrale. v. VI, Paris: CNRS, 1978, p. 279-340.

MONTEIRO, Juan Pablo Salgado Araújo. Análise de A capital federal. São 
João del-Rei: Departamento de Letras, Artes e Cultura da UFSJ, 2003. Trabalho de Iniciação Científica PIBIC/FAPEMIG.

MOREIRA, Inês Cardoso Martins. A dramaturgia de Suassuna: procedimentos analíticos. In: O Percevejo. Rio de Janeiro, UNIRIO, ano 8, nº 8, 2000, p. 150-5. NEVES, João das. A análise do texto teatral. Rio de Janeiro: Inacen, 1987. Nova edição: Rio de Janeiro: Europa, 1997.

PAES LEME, André. Entrevista concedida

PALLOTTINI, Renata. Introdução à dramaturgia. São Paulo: Brasiliense, 1988.

PAVIS, Patrice. Dicionário de teatro. São Paulo: Perspectiva, 1999.

PAVIS, Patrice. A análise dos espetáculos. Teatro, música, dança, dança-teatro, cinema. São Paulo: Perspectiva, 2003.

ROSENFELD, Anatol. Que é mise-en-scène? In: Prismas do teatro. São Paulo: Perspectiva, EDUSP; Campinas: Ed. UNICAMP, 1993, p. 75-106. RUIZ, Roberto. 1988.

RYNGAERT, Jean-Pierre. Introdução à análise do teatro. São Paulo : Martins Fontes, 1995.

SILVA, Daniel Marques da. "Precisa arte e engenho até..." - um estudo sobre a composição do personagem-tipo através de burletas de Luiz Peixoto. Rio de Janeiro, 1998. Dissertação (Mestrado em Teatro), UNIRIO.

TORRES, Walter Lima. Introdução histórica: o ensaiador, o diretor e o encenador. In: Folhetim, Rio de Janeiro, no 9, p. 61-71, jan.-abr. 2001. UBERSFELD, Anne. Lire le théâtre. Paris: Belin, 1996. 3 v.

\section{Notas}

2 Os bolsistas são respectivamente: Juan Pablo Salgado Araújo Monteiro, Manuela Sabino de Freitas e Valdirene de Paiva Paula. O trabalho do primeiro bolsista iniciou em março de 2003 e o projeto proposto tem como título Nos tempos de Artur Azevedo: aportes históricos e culturais à análise de A capital federal. O trabalho das outras duas bolsistas iniciou em agosto de 2003.

3 A capital federal foi representada por uma grande variedade de companhias teatrais, quando pensamos do ponto de vista cultural: passou tanto pelo circo-teatro quanto por palcos mais refinados como o do Teatro São Pedro de Alcântara e o do Centro Cultural Banco do Brasil. O mambembe foi escolhida sobretudo por seu caráter metateatral e pela possibilidade de contrastar a montagem de 1959 pelo Teatro dos Sete no palco do Teatro Municipal do Rio de Janeiro com as várias montagens de estudantes formandos em Teatro, como a do diretor Amir Haddad no Teatro Cacilda Becker, no Rio de Janeiro. A filha de Maria Angu foi escolhida pela possibilidade de pensar um diálogo entre a cultura francesa e a brasileira.

4 "In the nineteenth century, theatre was predominantly defined by its capacity to convey or mediate literary works of art".

5 Sobre as diferenças entre ensaiador, diretor teatral e encenador, cf. Torres (2001) e Rosenfeld (1993). 
6 Em relação à valorização da teatralidade, podemos citar como exemplos Edward Gordon Craig, Adolphe Appia, Vsevolod Meyerhold, Bertolt Brecht entre outros.

7 Em 1968, houve uma nova edição revista.

8 Ubersfeld transpõe procedimentos metodológicos do campo da lingüística e da análise do discurso para o campo teatral, utilizando a grade de Hjelmslev (destinador/destinatário, sujeito/objeto, oponente/adjuvante) para analisar peças teatrais.

9 Já são muitos os autores que trabalham com as diferenças entre palco e página: Chartier (2002), Pavis (2003), Ryngaert (1995) são apenas alguns deles.

10 O projeto do primeiro Grupo foi elaborado pela professora Dra. Beti Rabetti (Maria de Lourdes Rabetti) e vem sendo coordenado desde o ano 2000 pelo prof. Alberto Tibaji (Alberto Ferreira da Rocha Junior). Cf. também CONGRESSO Brasileiro da Associação Brasileira de Pesquisa e Pós-graduação em Artes Cênicas, 2001 e 2002.

11 Chamamos de "clássicos" os textos cômicos consagrados pela história de nosso teatro e pela crítica.

12 A maioria das fontes primárias - recortes de nornais, fotos, anúncios, cartazes, vídeo etc. - foi copiada da Biblioteca da FUNARTE, da Seção de Periódicos da Fundação Biblioteca Nacional e dos arquivos da Sarau - agência de cultura brasileira.

13 O projeto é coordenado pela profa. Dra. Beti Rabetti (Maria de Lourdes Rabetti), pesquisadora do CNPq e professora do Programa de Pós-graduação em Teatro da UNIRIO. Daniel Marques da Silva (1998) também utiliza os procedimentos de fabricação de comicidade para a compreensão de personagens-tipo. Encontramos ainda outra Dissertação de Mestrado que analisa peças cômicas a partir dos referidos procedimentos: Borges, 1991.

$14 \mathrm{O}$ item Fontes trata do material utilizado por Suassuna para a elaboração de suas peças. No caso, há uma predomínio dos livros de cordel e do cancioneiro popular nordestino. O item Movência trata da oralidade e da performance, marcas dos textos de teatro de revista estudados por Chiaradia.

15 Ao questionarmos a idéia de objetividade científica não pretendemos defender aquilo que Eco denomina superinterpretanção (1997).

16 Cf. Pavis (2003) e Kozwan (1978).

17 "Il faut reconnaître dans la "représentation" le mode d'être de l'œuvre d'art elle même".

18 "L'exécution d'un drame ne peut pas non plus être séparée du drame lui-même comme quelque chose qui n'appartiendrait pas à son être essentiel".

19 "La prétention à l'exactitude de toute représentation confirme simplement que la non-distinction entre la médiation de l'œuvre et l'œuvre elle-même constitue la véritable expérience de l'œuvre".

20 "L'étant qui n'est que dans la mesure où il ne cesse de devenir autre".

21 "Une continuité de sens qui reliel 'auvre d'art au monde de l'existence".

22 Verdade e método de Gadamer é anterior à aula inaugural proferida por Jauss em Kontanz em $1967 \mathrm{e}$ intitulada História da literatura como provocação à ciência literária, considerada o marco inicial da Teoria da Recepção. Sobre a dívida que Jauss tem em relação a Gadamer: "A teoria de Gadamer da experiência hermenêutica, a explicação histórica desta experiência na história dos conceitos humanísticos fundamentais, seu princípio de reconhecer na história do efeito (Wirkungsgeschichte) o acesso a toda compreensão histórica e a solução do problema da realização controlável da "fusão de horizontes" são os pressupostos metodológicos inquestionáveis, sem os quais o meu projeto seria impensável. (Jauss, 1979: 55).

23 "Le concept de littérature n'est pas entièrement sans référence à celui qui reçoit l'œuvre".

24 A última edição do livro é de 1997.

25 Nós estaríamos passando para uma nova estase, de acordo com a terminologia empregada por David Ball (1999).

26 Foram escolhidas as seguintes representações de A capital federal: 1897, 1909, 1915, 1927, 1972 e 1997.

27 Depois de Eusébio e Lola, os personagens que aparecem em mais cenas são Figueiredo e Benvinda, em

21 e 18 cenas respectivamente.

28 Seguem algumas outras distribuições: em 1909: Leonardo e Irene Esquirós; em 1972: Suely Franco e Lutero Luiz; em 1997: Louise Cardoso e Antônio Pedro.

29 Há trinta e uma cenas antes do encontro entre Lola e Eusébio e trinta e seis depois do encontro. A peça tem cem páginas e o encontro entre os dois acontece na quadragésima oitava página do texto.

30 Fantasia de príncipe de tipo burlesco e carnavalesco. 